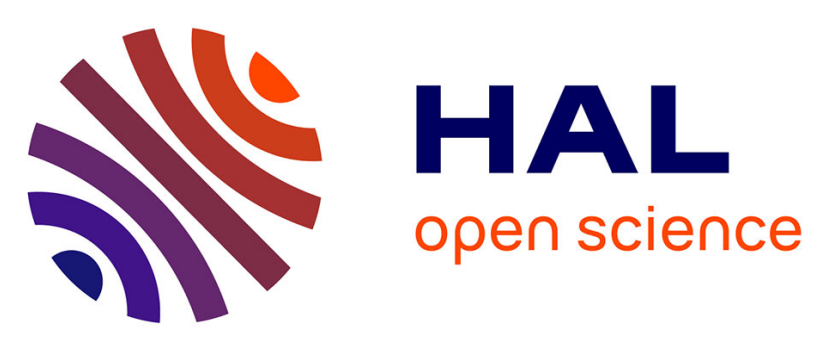

\title{
Experimental (XPS/STM) and theoretical (FLAPW) studies of model systems M1/4TiS2 (M=Fe, Co, Ni): influence of the inserted metal
}

Isabelle Baraille, Hervé Martinez, Yann Tison, Michel Loudet, Danielle Gonbeau

\section{To cite this version:}

Isabelle Baraille, Hervé Martinez, Yann Tison, Michel Loudet, Danielle Gonbeau. Experimental (XPS/STM) and theoretical (FLAPW) studies of model systems M1/4TiS2 (M=Fe, Co, Ni): influence of the inserted metal. Journal of Electron Spectroscopy and Related Phenomena, 2002, 125 (3), pp.181-196. 10.1016/S0368-2048(02)00136-6 . hal-03225289

\section{HAL Id: hal-03225289}

\section{https://hal-univ-pau.archives-ouvertes.fr/hal-03225289}

Submitted on 12 May 2021

HAL is a multi-disciplinary open access archive for the deposit and dissemination of scientific research documents, whether they are published or not. The documents may come from teaching and research institutions in France or abroad, or from public or private research centers.
L'archive ouverte pluridisciplinaire HAL, est destinée au dépôt et à la diffusion de documents scientifiques de niveau recherche, publiés ou non, émanant des établissements d'enseignement et de recherche français ou étrangers, des laboratoires publics ou privés.

\section{(1) $(1) \Theta$}

Distributed under a Creative Commons Attribution - NonCommercial - NoDerivatives 44.0 


\title{
Experimental (XPS/STM) and theoretical (FLAPW) studies of model systems $\mathrm{M}_{1 / 4} \mathrm{TiS}_{2}(\mathrm{M}=\mathrm{Fe}, \mathrm{Co}, \mathrm{Ni})$ : influence of the inserted metal
}

\author{
H. Martinez*, Y. Tison, I. Baraille, M. Loudet, D. Gonbeau \\ LCTPCM/CNRS UMR 5624, Helioparc Pau-Pyrénées, 2 avenue du Président Angot, 64053 Pau Cedex 9, France
}

Received 22 February 2002; received in revised form 13 May 2002; accepted 15 May 2002

\begin{abstract}
The effects of metal insertion (iron, cobalt and nickel) into 1T-CdI - type $\mathrm{TiS}_{2}$ layered crystals, expressed as $\mathrm{M}_{x} \mathrm{TiS}_{2}$, have been studied by X-ray photoelectron spectroscopy (XPS), scanning tunneling microscopy (STM) and band structure calculations (FLAPW method). The stoichiometry $x=1 / 4$ was chosen because of specific crystallographic features of the compounds studied. We focused our interest on the role played by chalcogen atoms. S $2 \mathrm{p}$ core spectra are found to depend strongly on their chemical surroundings ( $\mathrm{Ti}$ or $\mathrm{Ti}$ and $\mathrm{M}$ ) and on the guest metal. We imaged the top sulfur plane (001) for $\mathrm{Fe}_{1 / 4} \mathrm{TiS}_{2}, \mathrm{Co}_{1 / 4} \mathrm{TiS}_{2}$ and $\mathrm{Ni}_{1 / 4} \mathrm{TiS}_{2}$ and note that the results also depend on the compound considered. Theoretical calculations have been carried out in order to improve our knowledge of the electronic structure of $\mathrm{M}_{1 / 4} \mathrm{TiS}_{2}$ compounds and attempts are made to rationalize the experimental data.
\end{abstract}

(C) 2002 Elsevier Science B.V. All rights reserved.

Keywords: Insertion; Scanning tunneling microscopy (STM); X-ray photoelectron spectroscopy (XPS); Core peaks; Valence bands; Calculated densities of states

\section{Introduction}

Several studies of the electronic properties of layered transition metal dichalcogenides $\left(1 \mathrm{~T}-\mathrm{CdI}_{2}-\right.$ type $\left.\mathrm{TiS}_{2}\right)$ and their inserted phases $\mathrm{M}_{x} \mathrm{TiS}_{2}(\mathrm{M}=3 \mathrm{~d}$ metals, $x=0$ to 1 ) have been undertaken because of their anisotropic magnetic and electronic properties. From a crystallochemical point of view, the host compound $\left(\mathrm{TiS}_{2}\right)$ can act as a lattice for the insertion of electron-donating species such as alkali metals or

\footnotetext{
*Corresponding author. Tel.: +33-5-5992-3081; fax: +33-55980-8344.

E-mail address: herve.martinez@univ-pau.fr (H. Martinez).
}

transition metals [1-4]. The type and concentration of inserted species have a significant effect on the physical properties of the new structure which results from charge transfer between the guest and the host structure $[5,6]$. Spectroscopic, electronic and theoretical studies [5-17] have been reported in the literature and have contributed to a better understanding of the electronic structure of some inserted phases.

Electronic and structural modification phenomena induced by insertion (in various types of materials and guest species) have been studied in our group for several years $[14,15,18-20]$. These studies where first supported by XPS and theoretical calculations. For the past few years, we have undertaken STM/ 
AFM studies on layered, misfit and inserted compounds $[21,22]$.

This work reports systematic X-ray photoelectron spectroscopy (XPS), room temperature UHV scanning tunneling microscopy and theoretical studies (WIEN97 code) on the inserted compounds $\mathrm{Fe}_{1 / 4} \mathrm{TiS}_{2}, \mathrm{Co}_{1 / 4} \mathrm{TiS}_{2}$ and $\mathrm{Ni}_{1 / 4} \mathrm{TiS}_{2}$, widely less studied than the $\mathrm{M}_{1 / 3} \mathrm{TiS}_{2}$ specific stoichiometry. As these samples present the same specific crystallochemical features (especially different sites for sulfur and titanium atoms), we have interpreted the evolution of their electronic characteristics, according to the guest metal inserted. The originality of this paper lies in the investigation of these compounds by XPS/STM and theoretical calculations, with special interest in the role of chalcogen atoms, in contrast to previous studies which focused on the metal atoms.

\section{Crystallographic structure}

Titanium disulfide is one of the transition metal dichalcogenides that crystallize in the $\mathrm{CdI}_{2}$ system $(P \overline{3} m 1$, space group No. 164). It can be described as a simple juxtaposition of stacked layers along a crystallographic axis. The slabs of octahedra consist of two anionic layers sandwiching a metallic one. The anionic layers have hexagonal close packing with the metal occupying half of the octahedral sites. The vacant octahedral sites form the van der Waals gap. This structure suggests that this compound is a good candidate for insertion (nickel, cobalt or iron in our case) by occupation of free octahedral sites. The lattice parameters of the $\mathrm{TiS}_{2}$ lattice were determined by X-ray diffraction [5,6,23,24] and are summarized in Table 1.

For $\mathrm{M}_{1 / 4} \mathrm{TiS}_{2}(\mathrm{M}=\mathrm{Fe}, \mathrm{Co}, \mathrm{Ni})$, superstructure ordering of the $\mathrm{M}$ ion in the van der Waals gap was observed. The structure crystallizes in the same space group $P \overline{3} m 1$ (space group No. 164) as $\mathrm{TiS}_{2}$

Table 1

Lattice parameters determined by X-ray diffraction data $[5,6,25,26]$

\begin{tabular}{lllll}
\hline & $\mathrm{TiS}_{2}$ & $\mathrm{Fe}_{1 / 4} \mathrm{TiS}_{2}$ & $\mathrm{Co}_{1 / 4} \mathrm{TiS}_{2}$ & $\mathrm{Ni}_{1 / 4} \mathrm{TiS}_{2}$ \\
\hline$a=b(\AA)$ & 3.409 & 6.836 & 6.790 & 6.764 \\
$c(\AA)$ & 5.685 & 5.708 & 5.636 & 5.678 \\
\hline
\end{tabular}

and the substructure forms a lattice with parameters $2 a \times 2 a$ (where ' $a$ ' is the $\mathrm{TiS}_{2}$ parameter) in the hexagonal $(a, b)$ plane. The basis of the unit cell is composed of four titanium atoms, eight sulfur atoms and one nickel (cobalt or iron) atom (Fig. 1 represents the basal plane projection of the inserted $\mathrm{M}_{1 / 4} \mathrm{TiS}_{2}$ phase). When the intercalation stage is first order, one of the titanium atoms in the unit cell (Ti1 localized in site $1 a$; Table 2) is aligned with the nickel (cobalt or iron) metal atom while the three others (Ti2, Ti3, Ti4), located in site $3 e$ (Table 2), are below or above the empty octahedral sites of the van der Waals gap. This structure is based on stacking in plane $(a, b)$ of $\mathrm{TiS}_{2}$ slabs built from edge sharing $\left[\mathrm{TiS}_{6}\right]$ octahedra and along the [001] direction from face-sharing $\left[\mathrm{MS}_{6}\right]$ and $\left[\mathrm{TiS}_{6}\right]$. We can differentiate two types of sulfur atoms: some of them (75\%), located in site $6 i$ (named S2; Table 2, Fig. 1), are coordinated to nickel (cobalt or iron) and three titanium atoms and the others $(25 \%)$, located in site $2 d$ (named S1; Fig. 1), have only three titanium atoms as first neighbors. The $\mathrm{M}_{1 / 4} \mathrm{TiS}_{2}$ lattice parameters and the atomic coordinates are given in Tables 1 and 2, respectively.

\section{Experimental and computational details}

The elements $\mathrm{Fe}(\mathrm{Co}, \mathrm{Ni}), \mathrm{Ti}$ and $\mathrm{S}$ were mixed in appropriate proportions and placed in a quartz tube, which was sealed under vacuum. The mixture was then heated to $1050{ }^{\circ} \mathrm{C}$ for 10 days and then slowly cooled to room temperature. An intermediate crushing of the product was necessary to obtain homogeneity. A small amount of iodine was then added to favor crystallization [25]. The single crystals obtained were in platelet shape and could be easily cleaved.

Chemical composition and phase purity determination were carried out with an electron microprobe mounted on a scanning electron microprobe.

The XPS analyses were performed with a Surface Science Instruments Spectrometer (model 301) using focused (diameter of the irradiated area $=300 \mu \mathrm{m}$ ) monochromated Al $\mathrm{K} \alpha$ radiation $(1486.6 \mathrm{eV})$. The residual pressure inside the analysis chamber was in the $5 \times 10^{-9} \mathrm{~Pa}$ range. The spectrometer was calibrated using the photoemission lines of gold $\mathrm{Au}$ 


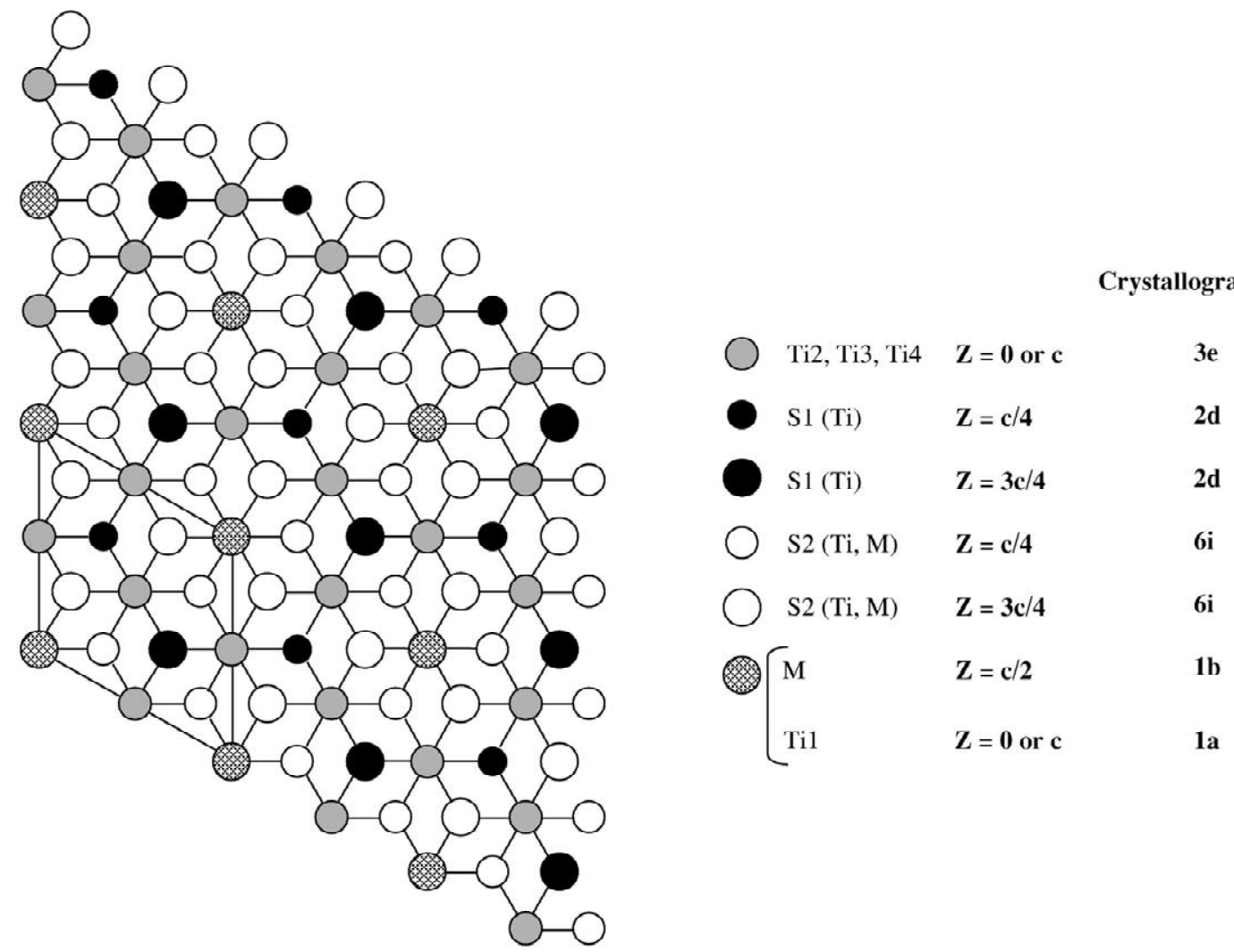

Fig. 1. Basal plane projection of the intercalated phases.

Table 2

Atomic coordinates, multiplicity and site symmetry of the $\mathrm{M}_{1 / 4} \mathrm{TiS}_{2}$ unit cell atoms

\begin{tabular}{lllll}
\hline Atom & $x$ & $y$ & $z$ & $\begin{array}{l}\text { Multiplicity, } \\
\text { site symmetry }\end{array}$ \\
\hline Ti1 (1) & 0 & 0 & 0 & $1 a, \overline{3 m}$ \\
Ti2 (2) & $1 / 2$ & 0 & 0 & $3 e, 2 / m$ \\
Ti3 (3) & 0 & $1 / 2$ & 0 & $3 e, 2 / m$ \\
Ti4 (4) & $1 / 2$ & $1 / 2$ & 0 & $3 e, 2 / m$ \\
S2 (1) & $1 / 3$ & $1 / 6$ & $-1 / 4$ & $6 i, m$ \\
S2 (2) & $5 / 6$ & $1 / 6$ & $-1 / 4$ & $6 i, m$ \\
S1 (3) & $1 / 3$ & $2 / 3$ & $-1 / 4$ & $2 d, 3 m$ \\
S2 (4) & $5 / 6$ & $2 / 3$ & $-1 / 4$ & $6 i, m$ \\
S2 (5) & $1 / 6$ & $1 / 3$ & $1 / 4$ & $6 i, m$ \\
S1 (6) & $2 / 3$ & $1 / 3$ & $1 / 4$ & $2 d, 3 m$ \\
S2 (7) & $1 / 6$ & $5 / 6$ & $1 / 4$ & $6 i, m$ \\
S2 (8) & $2 / 3$ & $5 / 6$ & $1 / 4$ & $6 i, m$ \\
Fe, Co or Ni & 0 & 0 & $1 / 2$ & $1 b, \overline{3} m$ \\
\hline
\end{tabular}

$4 \mathrm{f}_{7 / 2}=83.9 \mathrm{eV}$, with reference to the Fermi level) and copper $\left(\mathrm{Cu} 2 \mathrm{p}_{3 / 2}=932.5 \mathrm{eV}\right)$. For the $\mathrm{Au} 4 \mathrm{f}_{7 / 2}$ lines, the full width at half maximum (FWHM) was $0.86 \mathrm{eV}$. The peaks were recorded with a constant pass energy of $50 \mathrm{eV}$. All the compounds were sufficiently good conductors to preclude charging effects and the binding energies were obtained directly. The XPS signals were analyzed by using a peak synthesis program in which a non-linear background is assumed and the fitting peaks of the experimental curve are defined by a combination of Gaussian (80\%) and Lorentzian (20\%) functions. The curves fit for core peaks were obtained using fixed amplitude ratios, fixed spin-orbit splits and fixed FWHM ratios deduced from the analysis of reference compounds. It is to be noted that a minimum number of doublets has always been used in order to fit the experimental curves. Each compound was cleaved in a glove box filled with 
continuously purified nitrogen $\left(\mathrm{O}_{2}\right.$ and $\mathrm{H}_{2} \mathrm{O}$ level below 2 and 7 ppm, respectively) and fixed directly onto the introduction chamber of the spectrometer.

STM analyses were conducted in UHV using a commercial (VP from Park Scientific Instrument) scanning tunneling head, controlled by feedback electronics and software of conventional design. The residual pressure inside the analysis chamber was in the $5 \times 10^{-9} \mathrm{~Pa}$ range. Mechanically-sharpened $\mathrm{Pt} / \mathrm{Ir}$ tips were used. Atomic scale images were recorded in the constant current mode. STM observed images were filtered by using the fast Fourier transform (FFT) procedure to emphasize the periodic features of the pattern. In this procedure, the pronounced frequency patterns in the FFT power spectra were saved to construct an idealized image in the reverse transform. The graphite, used as calibration sample, always gave the correct periodicity. Height profiles were obtained along two lines at an angle of $120^{\circ}$. All the compounds were cleaved before their introduction into the UHV-STM chamber. Non-cleaved sample images exhibit the same features as cleaved samples but with a lower signal-to-noise ratio.

We have performed band-structure calculations using the full linear potential augmented plane wave (FLAPW) method, as implemented in the WIEN97 code developed by Blaha et al. [26]. Our calculations are based on density functional theory (DFT) within the generalized gradient approximation (GGA) [27] which is in most cases an improvement over LSDA (local spin density approximation). All calculations are well converged in terms of the size of the plane wave basis set and the $k$-point sampling within the irreducible part of the Brillouin zone. In these studies, we used 52 irreducible Brillouin zone $k$ points, angular moment of $L_{\max }=10$, and muffin-tin radii for the atomic species of $\mathrm{Ti}, \mathrm{Fe}, \mathrm{Co}, \mathrm{Ni}=2.0$ a.u., $\mathrm{S}=1.8$ a.u. The density of states (DOS) was obtained using the improved tetrahedron method given by Blöchl et al. [28].

\section{XPS results}

\subsection{Core peaks}

As stringent handling conditions were imposed to avoid contamination, a low oxygen content $(<2 \%)$ was found in all compounds. The results obtained for the main core peaks Ti 2p, M 2p, and $S 2 p$ of $\mathrm{Fe}_{1 / 4} \mathrm{TiS}_{2}, \mathrm{Co}_{1 / 4} \mathrm{TiS}_{2}$ and $\mathrm{Ni}_{1 / 4} \mathrm{TiS}_{2}$ (and $\mathrm{TiS}_{2}$ for comparison) are reported in Table 3 . The corresponding $\mathrm{S} 2 \mathrm{p}$ spectra are presented in Fig. 2 .

The $\mathrm{M} 2 \mathrm{p}_{3 / 2}(\mathrm{M}=\mathrm{Fe}, \mathrm{Co}, \mathrm{Ni})$ peaks (708.4/ $778.9 / 853.0 \mathrm{eV})$ in $\mathrm{M}_{1 / 4} \mathrm{TiS}_{2}$ appear at a higher binding energy than for metallic elements recorded in our spectrometer $(706.6 / 777.5 / 852.0 \mathrm{eV})$. This energetic shift reflects the presence of a positive charge on the metallic atom in the inserted compounds, in agreement with the guest-host classical charge transfer phenomena. We note the presence of satellite structures located at higher binding energies for the three compounds. The ratio between the intensity of the main peak and its satellite (equivalent for the three inserted compounds) is indicated in Table 3.

Table 3

Binding energies (eV) and FWHM (full width at half maximum) in brackets for the main core peaks and satellites

\begin{tabular}{lllll}
\hline $\mathrm{S} 2 \mathrm{p}_{3 / 2-1 / 2}$ & $\mathrm{TiS}_{2}$ & $\mathrm{Fe}_{1 / 4} \mathrm{TiS}_{2}$ & $\mathrm{Co}_{1 / 4} \mathrm{TiS}_{2}$ & $\mathrm{Ni}_{1 / 4} \mathrm{TiS}_{2}$ \\
\hline & $160.8-162.0$ & $160.6-161.8(76 \%)$ & $160.6-161.8(80 \%)$ & $160.6-161.8(78 \%)$ \\
& {$[0.8][0.9]$} & {$[1.0][1.1]$} & {$[1.0][1.1]$} & {$[1.0][1.1]$} \\
& & $161.7-162.8(24 \%)$ & $162.0-163.0(20 \%)$ & $162.1-163.2(22 \%)$ \\
& {$[1.1][1.2]$} & {$[1.1][1.2]$} & {$[1.1][1.2]$} \\
$\mathrm{Ti} 2 \mathrm{p}_{3 / 2-1 / 2}$ & & & $455.6-461.6$ \\
& $455.9-462.1$ & $455.5-461.5$ & $455.5-461.6$ & {$[2.4][2.4]$} \\
$\mathrm{M} 2 \mathrm{p}_{3 / 2}$ & {$[2.3][2.3]$} & {$[2.4][2.4]$} & $853.0[2.9]$ \\
$\mathrm{M}=\mathrm{Fe}, \mathrm{Co}, \mathrm{Ni}$ & & & $778.9[3.4]$ & $858.0(\mathrm{sat})[4.8]$ \\
& & $708.4[3.9]$ & $783.7(\mathrm{sat})[5.6]$ & $I \mathrm{~s} / \mathrm{Ip}=0.3$ \\
\hline
\end{tabular}

$I \mathrm{~s} / \mathrm{Ip}=$ intensity of satellite peak/intensity of primary peak. 

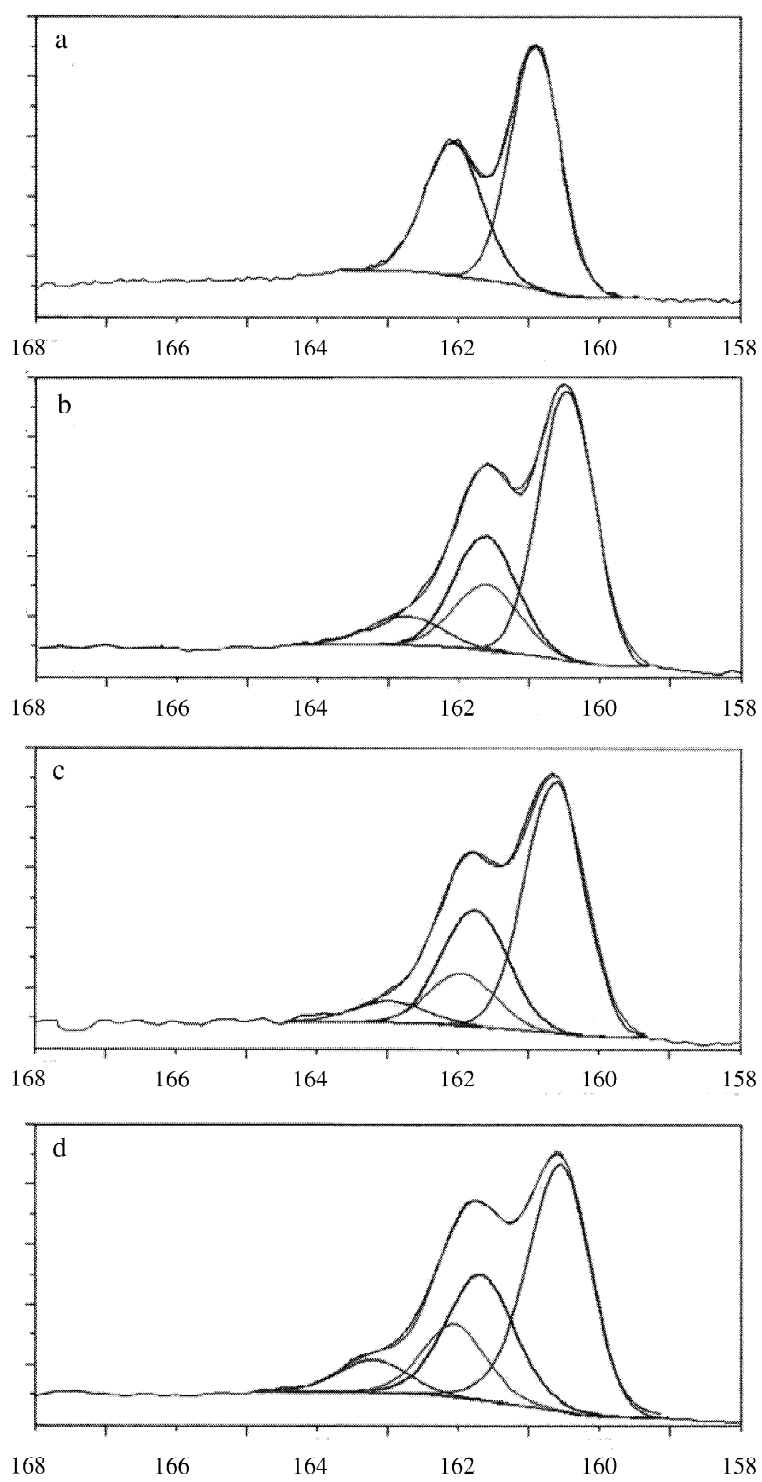

Binding energy (eV)

Fig. 2. $\mathrm{S} 2 \mathrm{p}_{3 / 2-1 / 2}$ core spectra for $\mathrm{TiS}_{2}$ (a), $\mathrm{Fe}_{1 / 4} \mathrm{TiS}_{2}$ (b), $\mathrm{Co}_{1 / 4} \mathrm{TiS}_{2}$ (c) and $\mathrm{Ni}_{1 / 4} \mathrm{TiS}_{2}$ (d).

The Ti $2 p$ core peaks for inserted compounds are clearly broadened with a slight shift of the maximum towards low binding energies compared with the host compound and show an asymmetric shape. Satellite structure is not clearly observed in that core energy range.

The $\mathrm{S} 2 \mathrm{p}_{3 / 2-1 / 2}$ peaks can be decomposed into two doublets for all the inserted compounds. The experimental ratio obtained for each sulfur type (76/ $24 \%$ for $\mathrm{Fe}_{1 / 4} \mathrm{TiS}_{2}, 80 / 20 \%$ for $\mathrm{Co}_{1 / 4} \mathrm{TiS}_{2}$ and 78/ $22 \%$ for $\mathrm{Ni}_{1 / 4} \mathrm{TiS}_{2}$ ) agrees with the theoretical crystallographic structure, in which the atoms named S2 and S1 are comprised of 75 and $25 \%$ of sulfur atoms, respectively. Consequently, the $\mathrm{S} 2 \mathrm{p}$ doublet on the high-energy side is associated with sulfur atoms in a metallic environment similar to the host structure $\mathrm{TiS}_{2}$. The more intense doublet is attributed to sulfur atoms coordinated with both titanium and the inserted metal; its lower binding energy reflects the appearance of a more negative charge. It is to be noted that in agreement with the bulk stoichiometry, the different chemical surroundings for sulfur atoms are clearly identified by XPS. In addition, they present some differences depending on the compounds considered. The split between the two doublets (3/2 components) is $1.0 \mathrm{eV}$ for $\mathrm{Fe}_{1 / 4} \mathrm{TiS}_{2}, 1.2 \mathrm{eV}$ for $\mathrm{Co}_{1 / 4} \mathrm{TiS}_{2}$ and $1.4 \mathrm{eV}$ for $\mathrm{Ni}_{1 / 4} \mathrm{TiS}_{2}$. Sulfur atoms seem to be the most differentiated in the case of $\mathrm{Ni}_{1 / 4} \mathrm{TiS}_{2}$.

\subsection{Valence bands}

The valence band spectra of $\mathrm{TiS}_{2}, \mathrm{Fe}_{1 / 4} \mathrm{TiS}_{2}$, $\mathrm{Co}_{1 / 4} \mathrm{TiS}_{2}$ and $\mathrm{Ni}_{1 / 4} \mathrm{TiS}_{2}$ are presented in Fig. 3 .

The valence spectrum of $\mathrm{TiS}_{2}$ presents two main bands separated by $9.5 \mathrm{eV}$. The broad band at lower binding energy exhibits a characteristic triplet structure, with three maxima located at 5.0, 3.3 and 2.2 $\mathrm{eV}$. On the high binding energy side, a single band is observed centered at $12.8 \mathrm{eV}$, with a FWHM (full width at half maximum) equal to $2.4 \mathrm{eV}$. This band is clearly broadened for $\mathrm{Fe}_{1 / 4} \mathrm{TiS}_{2}$ (FWHM: $2.8 \mathrm{eV}$ ), $\mathrm{Co}_{1 / 4} \mathrm{TiS}_{2}$ (FWHM: $2.9 \mathrm{eV}$ ) and $\mathrm{Ni}_{1 / 4} \mathrm{TiS}_{2}$ (FWHM: $2.9 \mathrm{eV})$, with an asymmetric shape towards high binding energies.

In the valence band peaks of $\mathrm{Fe}_{1 / 4} \mathrm{TiS}_{2}$, we notice the appearance of a new contribution (compared with the host compound $\mathrm{TiS}_{2}$ ) on the low binding energy side, which leads to an electronic density at the Fermi level reflecting a metallic behavior. This new contribution is attributed to the influence of the inserted metal. A similar spectrum has been observed previously for $\mathrm{Fe}_{1 / 3} \mathrm{TiS}_{2}[14,15]$ except that a more pronounced structure has been observed near $E_{\mathrm{F}}$ (in 

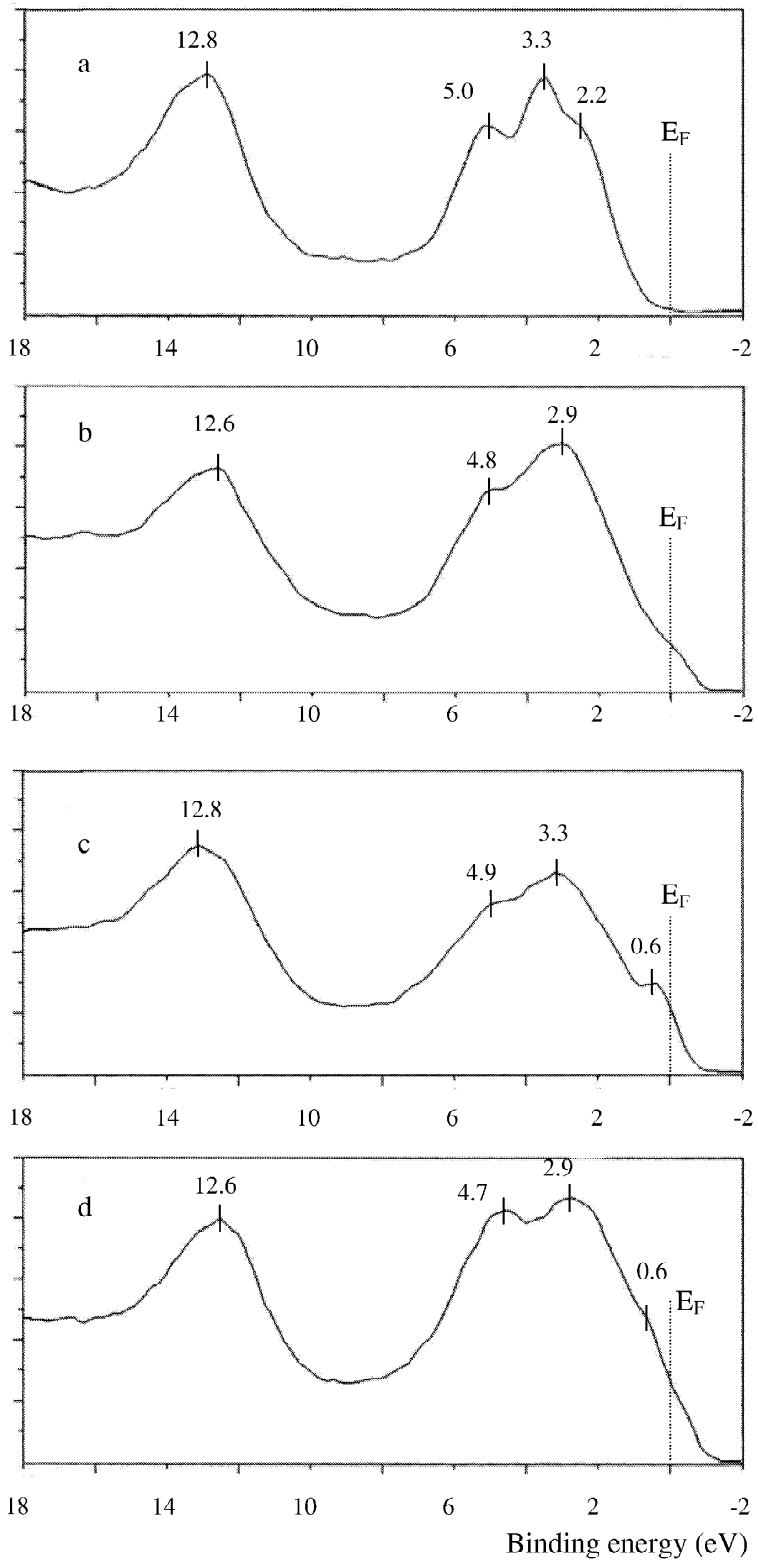

Fig. 3. XPS valence bands of $\mathrm{TiS}_{2}$ (a), $\mathrm{Fe}_{1 / 4} \mathrm{TiS}_{2}$ (b), $\mathrm{Co}_{1 / 4} \mathrm{TiS}_{2}$ (c) and $\mathrm{Ni}_{1 / 4} \mathrm{TiS}_{2}$ (d).

agreement with a higher concentration of the inserted species).

For $\mathrm{Co}_{1 / 4} \mathrm{TiS}_{2}$ and $\mathrm{Ni}_{1 / 4} \mathrm{TiS}_{2}$, the relative intensity of the maxima located at 4.9 and $4.7 \mathrm{eV}$ (Fig. 3) increases compared with $\mathrm{TiS}_{2}$ and $\mathrm{Fe}_{1 / 4} \mathrm{TiS}_{2}$ (5.0 and $4.8 \mathrm{eV}$; Fig. 3). Furthermore, the influence of the inserted metal ( $\mathrm{Co}$ and $\mathrm{Ni}$ ) on the electron density at the Fermi level seems to be more pronounced than for $\mathrm{Fe}_{1 / 4} \mathrm{TiS}_{2}$.

\section{STM results}

Atomic scale imaging of $\mathrm{TiS}_{2}$ was carried out for comparison with and to calibrate images from the inserted compounds $\mathrm{M}_{x} \mathrm{TiS}_{2}$. Images and associated height profiles are presented in Figs. 4 and 5. As expected, the STM scan for $\mathrm{TiS}_{2}$ (Fig. 4a) exhibits a hexagonal structure, regardless of the tunneling current $(0.2-2 \mathrm{nA})$ or the bias voltage applied to the substrate $(-300$ to $300 \mathrm{mV})$. The measured lattice spacing of $3.45 \AA$ is in agreement with the literature $\mathrm{X}$-ray diffraction data $[5,6]$. The surface chalcogen and the subsurface metal layers both have identical symmetries and lattice parameters. The origin of this image (and more generally of layered transitionmetal dichalcogenide images) remains controversial in terms of the role played by the different types of atoms. Considering only the electronic density near the Fermi level, images obtained with positive and negative polarization should reveal the structure formed by the two types of atoms. However, when the layered structure is considered, they are $1.5 \AA$ apart. We have shown by experimental and theoretical work [22] that the titanium atoms are too far from the tip to contribute to the tunneling current and so, only the plane of sulfur atoms is responsible for the image obtained. These results are in agreement with STM images obtained from several layered materials [29]. In addition, the image exhibits bright and dark zones with no specific symmetry or periodicity. The modulating intensity could be due to surface defects or different levels of the top sulfur atoms observed. In fact, the cohesion between atomic planes is partially due to electrostatic forces, which are not equal over the entire surface; so, all the sulfur atoms in the top plane are not at exactly the same height, so they may induce contrast differences in the image.

For the inserted compounds, the images of the top sulfur planes (001) do not depend on the tip polarization. Excellent atomic resolution was obtained for all $\mathrm{M}_{1 / 4} \mathrm{TiS}_{2}$ (Figs. 4 and 5) compounds, using bias 

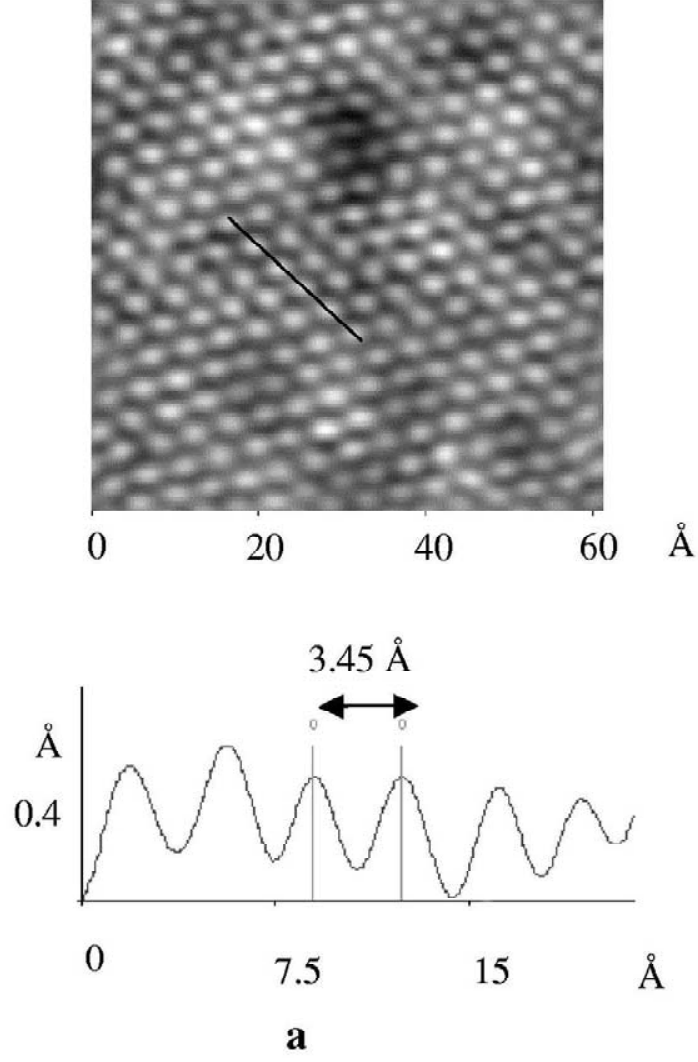
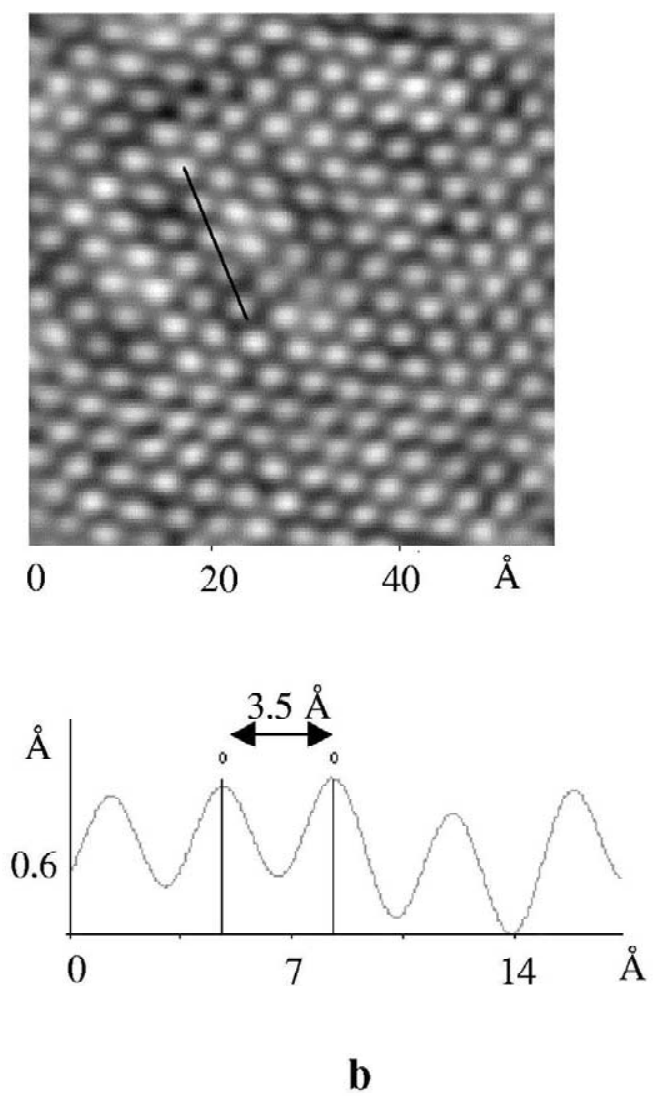

Fig. 4. STM images of $\mathrm{TiS}_{2}$ (a) and $\mathrm{Fe}_{1 / 4} \mathrm{TiS}_{2}$ (b) and associated height profiles.

voltage of -300 to $300 \mathrm{mV}$ and tunneling current of $0.1-3 \mathrm{nA}$.

The STM image of $\mathrm{Fe}_{1 / 4} \mathrm{TiS}_{2}$ (Fig. 4b) shows a unique sulfur atom hexagonal structure, with lattice spacing of $3.5 \AA$, similar to $\mathrm{TiS}_{2}$ (Fig. 4a). As for the host compound, the image exhibits bright and dark zones with no specific symmetry or periodicity. These zones could be due to non-equivalent electrostatic forces, which give rise to the cohesion between planes.

For $\mathrm{Co}_{1 / 4} \mathrm{TiS}_{2}$ and more clearly for $\mathrm{Ni}_{1 / 4} \mathrm{TiS}_{2}$, we notice two kinds of hexagonal structures (Fig. 5a) with lattice spacings of $2 a$ and $a$ (where $a$ is the unit cell parameter of $\mathrm{TiS}_{2}$ ). They are, respectively, represented by bright ( $25 \%$ of the image) and dark (75\% of the image) spots. These two kinds of hexagonal structures are confirmed by the Fourier transform (obtained from the unfiltered image) and the height profiles (Fig. 5a and b), which reveal two atom types, with different heights. These results are in agreement with the crystallographic structure for the different chemical environments of sulfur in the inserted compound. We can distinguish in the $\mathrm{Ni}_{1 / 4} \mathrm{TiS}_{2}$ (and less evident for $\mathrm{Co}_{1 / 4} \mathrm{TiS}_{2}$ ) image two different and alternated atom rows: one is composed of similar brightness spots and the other of alternately bright and dark spots. Furthermore, dark triangular shape zones are periodic all over the image; the unit cell seems to be formed by two triangular zones (Fig. 5b) with different brightness.

Note that all the STM scans of $\mathrm{Co}_{1 / 4} \mathrm{TiS}_{2}$ exhibit some defects (dark zones), certainly due to surface atom vacancies.

Thus, depending on the guest species inserted, STM analysis can exhibit two types of sulfur atoms, in agreement with the crystallographic structure. It is to be noted that sulfur atoms with the highest electronic density, according to XPS results, appear 

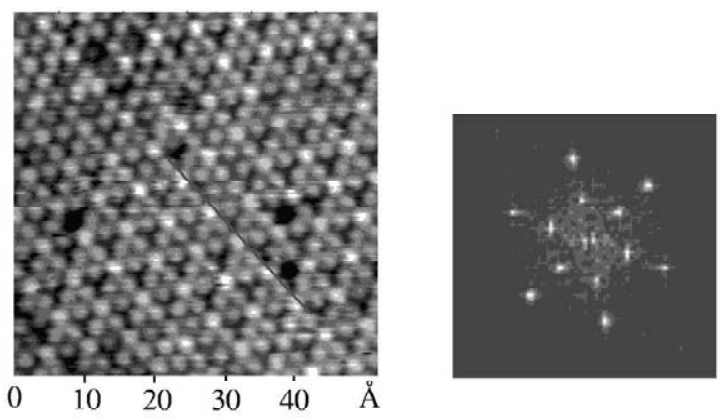
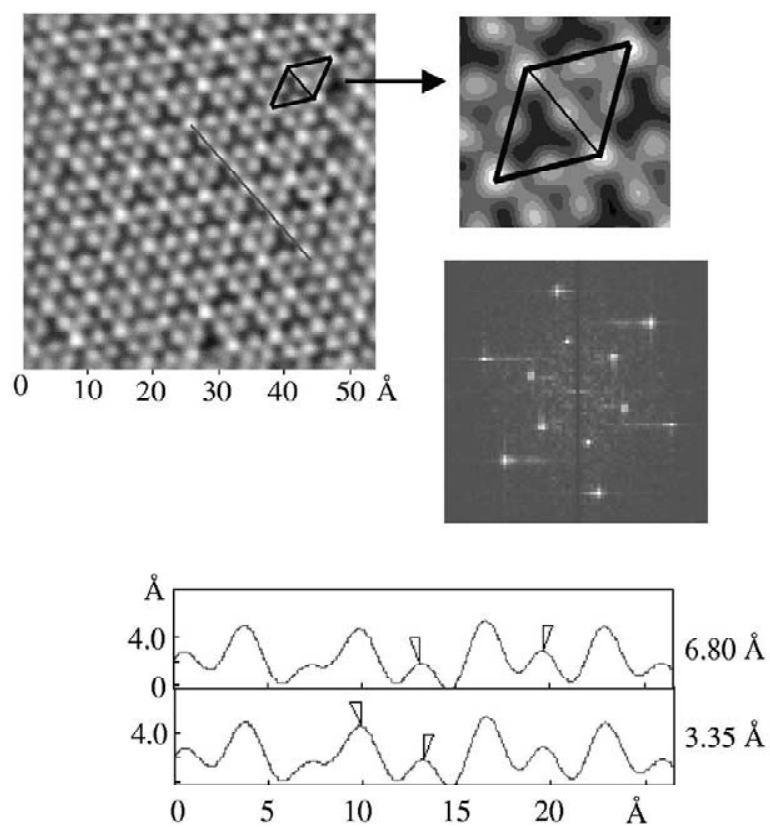

b

Fig. 5. STM images of $\mathrm{Co}_{1 / 4} \mathrm{TiS}_{2}$ (a) and $\mathrm{Ni}_{1 / 4} \mathrm{TiS}_{2}$ (b), FFT and associated height profiles. The unit cell of $\mathrm{Ni}_{1 / 4} \mathrm{TiS}_{2}$ is zoomed to highlight the two triangular zones.

as dark spots in the image, while bright spots seem to be characteristic of sulfur atoms with lower electronic density (located on the high binding energy side in the S $2 p$ XPS spectra).

\section{Theoretical results and discussion}

The previous experimental data have highlighted the influence of the nature of the inserted metal. In order to investigate this experimental observation more deeply and to improve our knowledge of the electronic structure of $\mathrm{M}_{1 / 4} \mathrm{TiS}_{2}$ compounds, we have performed FLAPW calculations.

First, it is of interest to analyze DOS curves for comparison with XPS valence bands. Non-modulated total DOS have been discussed taking account of the fact that cross-section weighted (occupied) DOS overemphasize the $3 \mathrm{~d}$ contributions, as observed in previous studies and noted in other works [30].

To avoid an exhaustive presentation, only the main DOS projected curves are reported. For $\mathrm{TiS}_{2}$, the results obtained (Figs. 6a and 7a,b) agree with previous theoretical calculations [31]. The main contribution of $\mathrm{S} 3 \mathrm{~s}$ orbital is observed between -13.2 and $-11.8 \mathrm{eV}\left(E-E_{\mathrm{F}}\right)$. The DOS between -5.1 and $0 \mathrm{eV}$ is derived from $\mathrm{S} 3 p$ orbitals with a non-negligible admixture of $\mathrm{Ti} 3 \mathrm{~d}$ orbitals. The characteristic triplet structure in the valence band spectrum is a result of these $\mathrm{S} 3 \mathrm{p}-\mathrm{Ti} 3 \mathrm{~d}$ interactions.

Compared to $\mathrm{TiS}_{2}$, our theoretical calculations for $\mathrm{M}_{1 / 4} \mathrm{TiS}_{2}$ compounds are in agreement with the observed increase in the experimental gap between the two main bands of the valence spectra (gaps are calculated between the maximum of the $\mathrm{S} 3 \mathrm{~s}$ band and the maximum of the middle of the characteristic triplet of $\mathrm{TiS}_{2}$ ).

- $\mathrm{TiS}_{2}$ : experimental: $9.5 \mathrm{eV}$; theoretical: $9.2 \mathrm{eV}$.

- $\mathrm{M}_{1 / 4} \mathrm{TiS}_{2}$ : experimental $\sim 9.7 \mathrm{eV}$; theoretical $\sim 10.1 \mathrm{eV}$.

Through DOS curve analysis, it is to be noted that between -14.2 and $-12.1 \mathrm{eV}\left(E-E_{\mathrm{F}}\right)$, two bands are 


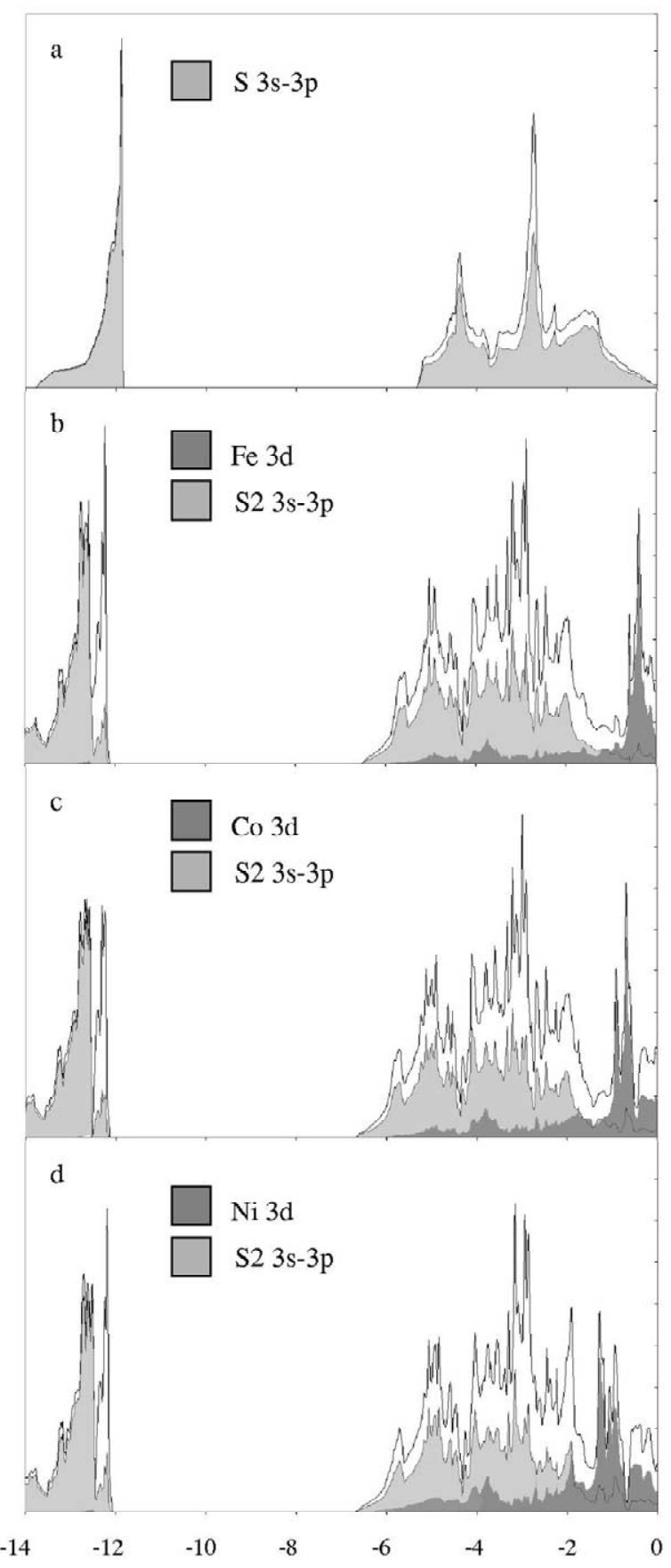

Fig. 6. Total and partial (sulfur 3p) DOS for $\mathrm{TiS}_{2}$ (a), $\mathrm{Fe}_{1 / 4} \mathrm{TiS}_{2}$ (b), $\mathrm{Co}_{1 / 4} \mathrm{TiS}_{2}$ (c) and $\mathrm{Ni}_{1 / 4} \mathrm{TiS}_{2}$ (d) (partial DOS for the three inserted compounds: sulfur $3 p$ in a mixed environment and $M 3 d$ orbital). observed for each $\mathrm{M}_{1 / 4} \mathrm{TiS}_{2}$ system studied. These appear characteristic of the two different chemical environments of sulfur atoms (respectively $\mathrm{S} 13 \mathrm{~s}$ and S2 3s orbital contributions), with slight participation from Ti $3 \mathrm{~d}$ orbital states. This result is consistent with the broadening of the experimental band on the high binding energy side, compared with the host structure (Fig. 3).

Between -6.8 and $0 \mathrm{eV}\left(E-E_{\mathrm{F}}\right)$, a broad band, which could be divided into two parts, includes the highest occupied states for $\mathrm{Fe}_{1 / 4} \mathrm{TiS}_{2}$ (Fig. 6 and 7): the first one (between -6.8 and $-1.4 \mathrm{eV}$ ) is mainly characteristic of the S 3p orbital but with some contributions from $\mathrm{Ti} 3 \mathrm{~d}$ and $\mathrm{Fe} 3 \mathrm{~d}$ orbitals. The second part, close to the Fermi level, primarily arises from iron $3 \mathrm{~d}$ localization with some participation of the Ti $3 d$ orbital and a weak contribution from the $S$ $3 p$ orbital. This result is consistent with the XPS analysis of the $\mathrm{Fe}_{1 / 4} \mathrm{TiS}_{2}$ valence band, which reveals the contribution of the inserted species at low binding energies. The Fermi level is located in the second part and leads to a high electronic density associated with $\mathrm{Fe} 3 \mathrm{~d}(39.5 \%)$, Ti $3 \mathrm{~d}(50.0 \%)$ and $\mathrm{S}$ $3 p(10.5 \%)$ orbitals. This result agrees with transport properties reported by Meakin et al. [32], which reflect a metallic behavior for this compound.

For $\mathrm{Co}_{1 / 4} \mathrm{TiS}_{2}$ and $\mathrm{Ni}_{1 / 4} \mathrm{TiS}_{2}$ (Figs. 6 and 7) the corresponding DOS curves between -6.8 and $0 \mathrm{eV}$ contain two parts, with similar contributions as $\mathrm{Fe}_{1 / 4} \mathrm{TiS}_{2}$ : S 3p orbitals between -6.8 and $-1.4 \mathrm{eV}$ and $\mathrm{Co} 3 \mathrm{~d} / \mathrm{Ni} 3 \mathrm{~d}$ orbitals between -1.4 and $0 \mathrm{eV}$. For both, as previously noted for $\mathrm{Fe}_{1 / 4} \mathrm{TiS}_{2}$, we observed that the M 3d orbitals contribute to the second part close to the Fermi level, in agreement with the experimental spectra.

In addition, the $M 3 d$ orbital contribution relative to the total DOS in the energy window -6.8 to $-4.3 \mathrm{eV}$ follows this order: $\mathrm{Ni}_{1 / 4} \mathrm{TiS}_{2}$ (9.5\%), $\mathrm{Co}_{1 / 4} \mathrm{TiS}_{2}(5.1 \%)$ and $\mathrm{Fe}_{1 / 4} \mathrm{TiS}_{2}$ (4.4\%). These features may be related to the enhancement found in the experimental spectra around 4.7 and $4.9 \mathrm{eV}$ for $\mathrm{Ni}_{1 / 4} \mathrm{TiS}_{2}$ and $\mathrm{Co}_{1 / 4} \mathrm{TiS}_{2}$, considering the fact that the photoionisation cross-section decreases in the following order: $\mathrm{Ni} 3 \mathrm{~d}(0.398$ in units of the $\mathrm{C} 1 \mathrm{~s}$ cross-section of 22.0 barns), Co 3d (0.266) and Fe 3d (0.171) [33] (S 3p: 0.0774; Ti 3d: 0.0126).

Furthermore, the presence of satellite structures (observed for M $2 p$ core peaks) in the valence band 


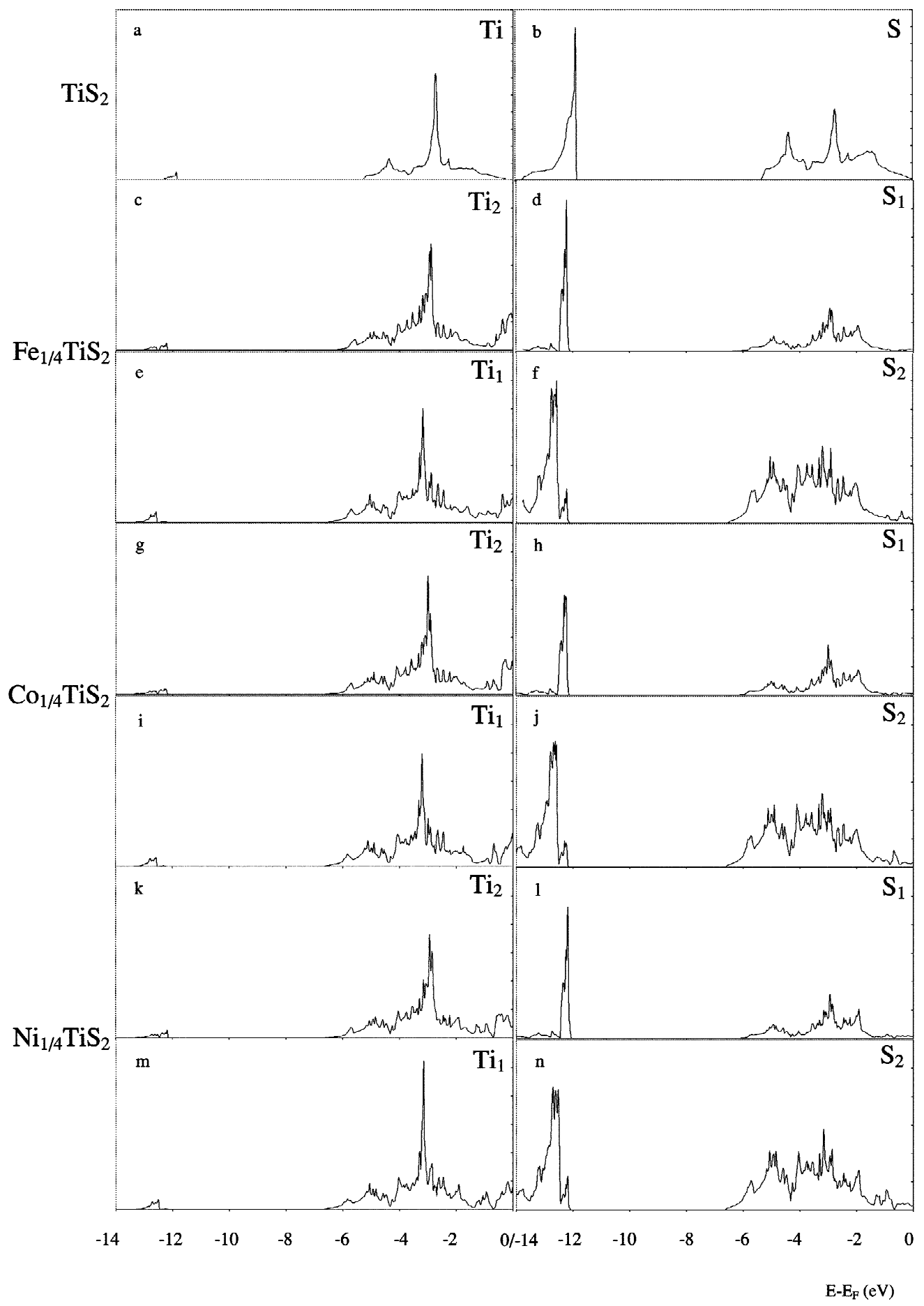

Fig. 7. Partial DOS for sulfur atoms ( 11 and $\mathrm{S} 2$ ) and titanium atoms (Ti1 and Ti2) in $\mathrm{TiS}_{2}(\mathrm{a}, \mathrm{b}), \mathrm{Fe}_{1 / 4} \mathrm{TiS}_{2}(\mathrm{c}-\mathrm{f}), \mathrm{Co}_{1 / 4} \mathrm{TiS}_{2}(\mathrm{~g}-\mathrm{j})$ and $\mathrm{Ni}_{1 / 4} \mathrm{TiS}_{2}(\mathrm{k}-\mathrm{n})$. 
may also contribute to the intensity increase for $\mathrm{Ni}_{1 / 4} \mathrm{TiS}_{2}$ and $\mathrm{Co}_{1 / 4} \mathrm{TiS}_{2}$. These structures can not be predicted by our theoretical approach; indeed in calculations using the density functional approach, the electronic correlation in the ground state is accounted for, but does not take into account final state effects associated with satellite structures. However, it is to be noted that previous studies on $\mathrm{Ni}_{1 / 3} \mathrm{TiS}_{2}$ by Fujimori et al. [11] using a $\mathrm{NiS}_{6}^{10-}$ cluster model have shown that the broadening of the
$\mathrm{Ni}_{1 / 3} \mathrm{TiS}_{2}$ valence band can be understood by configuration-interaction (CI) calculations.

On the whole, the main features of the valence spectra of the inserted compounds are reasonably well supported by analysis of the DOS curves.

In order to investigate more deeply the charge transfer and the interaction between atoms, we have undertaken a comparative analysis of charge density maps (Figs. 8 and 9) and partial charges. These last data are obtained from an integration of the $1(\mathrm{~m})$ like

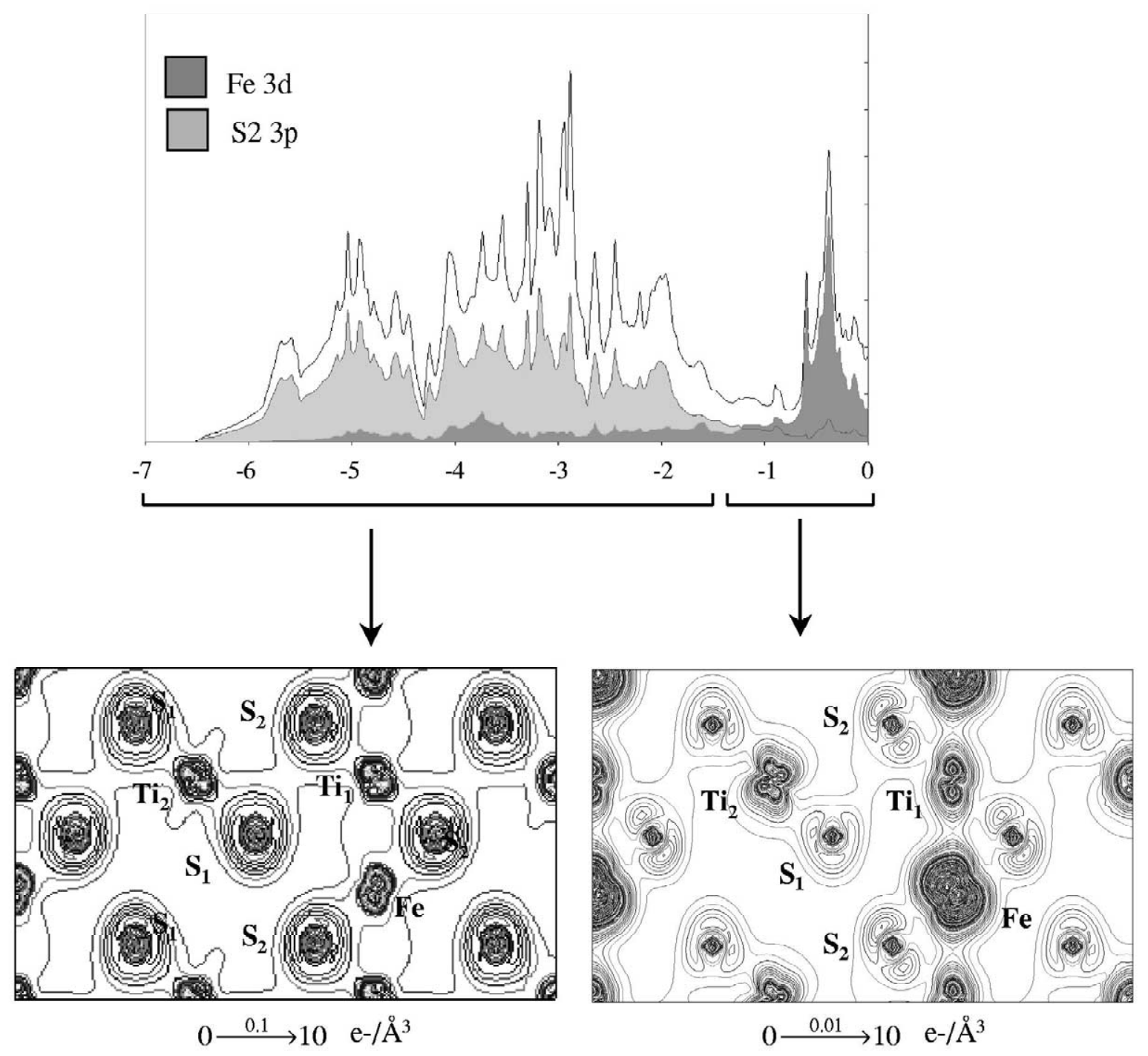

Fig. 8. DOS for $\mathrm{Fe}_{1 / 4} \mathrm{TiS}_{2}$ and partial density plots for the two different energy regions. 

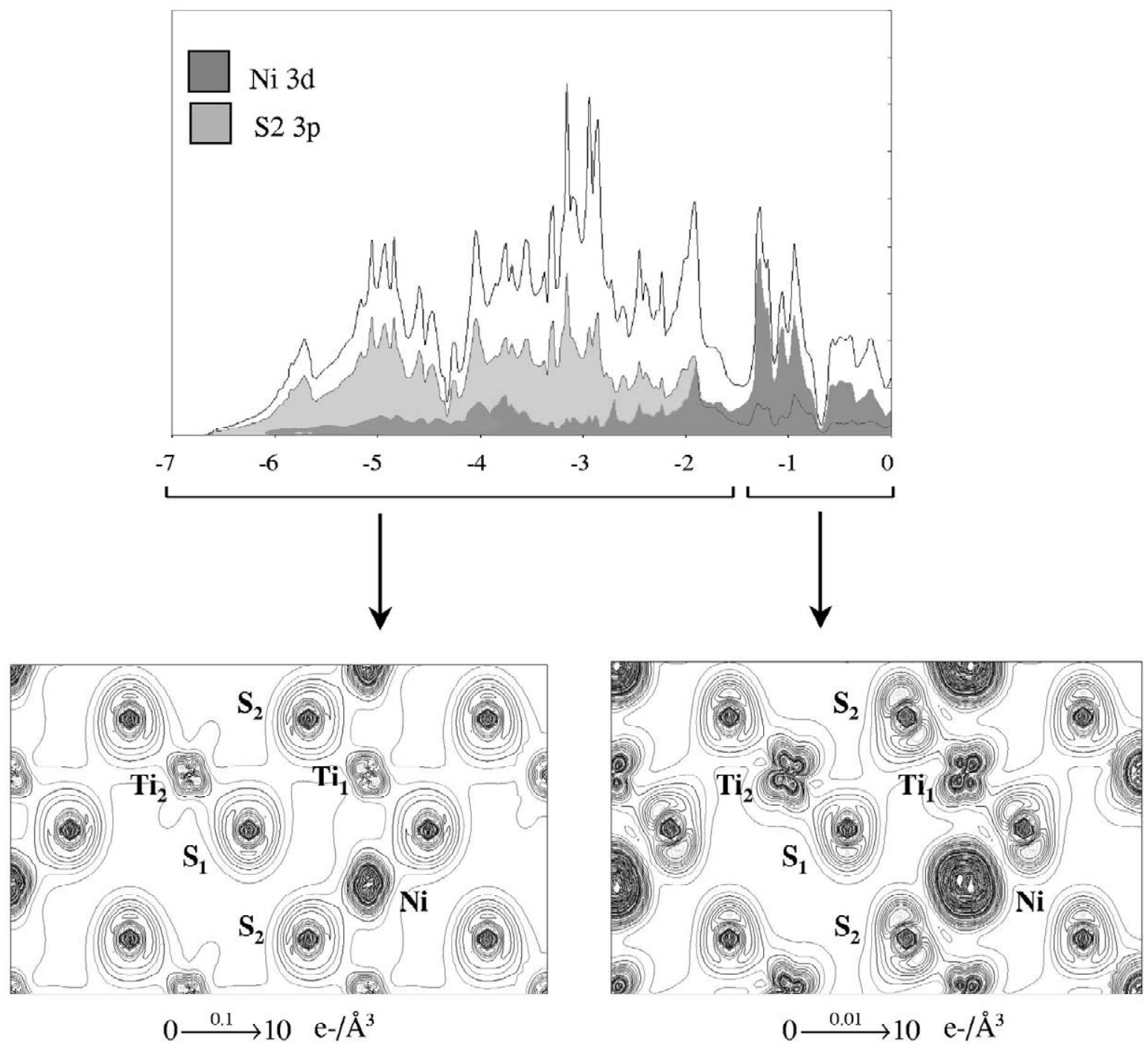

Fig. 9. DOS for $\mathrm{Ni}_{1 / 4} \mathrm{TiS}_{2}$ and partial density plots for the two different energy regions.

charge density over the respective atomic spheres. This corresponds to a spatial decomposition of the electronic charge and since delocalized wavefunctions are only partly confined to the atomic spheres, a lot of charge lies outside the spheres and thus cannot be analyzed further. Therefore, one must be careful in the interpretation of these partial charges. However, these data are valuable [34] when we compare a series of related compounds as in this work.

A positive character is observed for iron, cobalt and nickel atoms (around +1.8 e- for each) with reference to their ground state. This is consistent with the classical view of a charge transfer from the inserted species to the host lattice. The increase of their respective net charge is in agreement with the chemical shift observed towards high binding energies for the $\mathrm{M} 2 \mathrm{p}_{3 / 2}$ peaks (when referenced to the metallic elements).

Considering titanium atoms, it is to be remembered that in the basic lattice of $\mathrm{M}_{1 / 4} \mathrm{TiS}_{2}$, one of the titanium atoms (Ti1) is aligned with the guest atom along the [001] direction, while the other three (Ti2, Ti3, Ti4) are below (or above) empty octahedral sites 
of the van der Waals gap. The charge transfer from the inserted metal to the host lattice is recovered partially by titanium atoms, which become charged (in comparison to the same atoms in $\mathrm{TiS}_{2}$ ). This phenomenon is confirmed by partial charge analysis: $\mathrm{Ti}$ (from $\mathrm{TiS}_{2}$ ): 19.43; Ti1 and $\mathrm{Ti} 2$ (from $\mathrm{Fe}_{1 / 4} \mathrm{TiS}_{2}$ ): 19.48 and 19.46; Ti1 and $\mathrm{Ti} 2$ (from $\mathrm{Co}_{1 / 4} \mathrm{TiS}_{2}$ ): 19.50 and 19.48; Ti1 and Ti2 (from $\mathrm{Ni}_{1 / 4} \mathrm{TiS}_{2}$ ): 19.50 and 19.48 . The partial population of titanium atoms d levels (Ti1 and Ti2) after insertion is clearly underlined by an electronic density at the Fermi level compared with DOS associated to titanium atoms from $\mathrm{TiS}_{2}$ (Fig. 7). Only small differences exist between Ti1, and Ti2,3,4 DOS curves for each inserted compound (Fig. 7). However, the Ti1 3d contribution to the total DOS is slightly higher than the Ti2 $3 \mathrm{~d}$ contribution for each compound $\left(\mathrm{Fe}_{1 / 4} \mathrm{TiS}_{2}\right.$ : Ti1: 5\%; Ti2: 4.8\%; $\mathrm{Co}_{1 / 4} \mathrm{TiS}_{2}$ : Ti1: $4.9 \%$; Ti2: $4.7 \% ; \mathrm{Ni}_{1 / 4} \mathrm{TiS}_{2}$ : Ti1: 4.9\%; Ti2: $4.7 \%$ ). The charge transfer from $\mathrm{M}$ to Ti1 is then slightly higher when titanium atoms are aligned with the guest species. These results could be one argument to explain the broadening and the asymmetric shape of the $\mathrm{Ti} 2 \mathrm{p}$ core peaks. Note that previous work [11] on $\mathrm{Ni}_{1 / 3} \mathrm{TiS}_{2}$ has also considered final state effects as well (which could not be predicted by our theoretical approach) to explain the Ti $2 p$ core features.

The main difference between the three compounds is the nature of the $3 \mathrm{~d}$ orbitals involved in the charge transfer $\mathrm{M}$ to Ti1; this phenomenon is revealed at the level of the Ti1 $3 \mathrm{dz}^{2}$ for $\mathrm{Fe}_{1 / 4} \mathrm{TiS}_{2}$ whereas all the Ti $3 \mathrm{~d}$ orbitals are involved without any clear differentiation in $\mathrm{Co}_{1 / 4} \mathrm{TiS}_{2}$ and $\mathrm{Ni}_{1 / 4} \mathrm{TiS}_{2}$.

\begin{tabular}{lllll} 
& $\mathrm{TiS}_{2}$ & $\mathrm{Fe}_{1 / 4} \mathrm{TiS}_{2}$ & $\mathrm{Co}_{1 / 4} \mathrm{TiS}_{2}$ & $\mathrm{Ni}_{1 / 4} \mathrm{TiS}_{2}$ \\
\hline Ti1 3dz $/$ & $0.16 / 1.44$ & $0.31 / 1.50$ & $0.26 / 1.51$ & $0.22 / 1.51$ \\
Ti1 3d & & & & \\
partial charge & & & &
\end{tabular}

The charge density map in the (110) plane of $\mathrm{Fe}_{1 / 4} \mathrm{TiS}_{2}$ and $\mathrm{Ni}_{1 / 4} \mathrm{TiS}_{2}$ (Figs. 8 and 9) in the energy window -1.4 to $0 \mathrm{eV}\left(E-E_{\mathrm{F}}\right)$ supports the previous comments. This energy region corresponds to the maximum participation of $\mathrm{Ti}$ and $\mathrm{M} d$ orbitals to the total DOS. The directional character of the charge transfer is undoubtedly more pronounced for the iron inserted compound than for nickel (or cobalt, not presented because features are the same as $\mathrm{Ni}_{1 / 4} \mathrm{TiS}_{2}$ ).

The partial charge analysis carried out over sulfur atoms exhibits no difference between sulfur atoms named S1 and sulfur from the host compound $\mathrm{TiS}_{2}$. Small differences are observed for sulfur atoms named S2: the most important is for $\mathrm{Ni}_{1 / 4} \mathrm{TiS}_{2}$ where $\Delta\left(q_{\mathrm{S} 2}-q_{\mathrm{S} 1}\right)=3.10^{-2}$. In addition, differentiated DOS curves (Fig. 7) are computed for the partial density of states associated with S1 and S2 atoms for the three inserted compounds (Fig. 7d,f,h,j,l,n). The partial DOS curves for S1 atoms exhibit a 'triplet' shape, similar to the one of sulfur atoms in $\mathrm{TiS}_{2}$ (Fig. 6a), whereas the partial DOS curves for S2 atoms are different (Fig. 7f,j,n) from that of the host compound (Fig. 6a). Sulfur atoms in a mixed metallic environment (one $\mathrm{M}$ and three $\mathrm{Ti}$ atoms) are then clearly identified. These results support the previous $\mathrm{S} 2 \mathrm{p}$ core peaks analysis. The interacting orbitals ( $\mathrm{Ti}$ $3 \mathrm{~d} / \mathrm{S} 3 \mathrm{p}$ or Ti $3 \mathrm{~d} / \mathrm{M} 3 \mathrm{~d} / \mathrm{S} 3 \mathrm{p}$ ) involved in the energy range $\left(E-E_{\mathrm{F}}=-6.8\right.$ to $\left.-1.4 \mathrm{eV}\right)$ are then different depending on the sulfur atoms concerned. We noted previously in the experimental XPS section that the energy splitting between the two doublets of sulfur atoms increases from $\mathrm{Fe}_{1 / 4} \mathrm{TiS}_{2}, \mathrm{Co}_{1 / 4} \mathrm{TiS}_{2}$ to $\mathrm{Ni}_{1 / 4} \mathrm{TiS}_{2}$. This effect could be explained by the magnitude of interactions between S2 (sulfur in a mixed environment) $3 p$ and the metal $3 \mathrm{~d}$ orbitals concerned. Fig. 6 presents the total and partial (S2 3s, S2 3p, M 3d) DOS for the inserted compounds. By integrating these curves in the energy range $\left(E-E_{\mathrm{F}}=-6.8\right.$ to $\left.-1.4 \mathrm{eV}\right)$, the following results have been obtained for the relative S2 3p and M 3d participations in the total DOS:

\begin{tabular}{llll} 
& $\begin{array}{l}\text { S2 (Ti, M) 3p } \\
(\%)\end{array}$ & M 3d $(\%)$ & Ratio \\
\cline { 2 - 4 } & 66.8 & 7.0 & \\
$\mathrm{Fe}_{1 / 4} \mathrm{TiS}_{2}$ & 64.8 & 9.1 & 0.10 \\
$\mathrm{Co}_{1 / 4} \mathrm{TiS}_{2}$ & 61.3 & 14.1 & 0.14 \\
$\mathrm{Ni}_{1 / 4} \mathrm{TiS}_{2}$ & & & 0.23
\end{tabular}

These results highlighted different degrees of interaction magnitude according to the nature of the inserted atom and help to explain the different energy splitting observed by $\mathrm{S} 2 \mathrm{p}$ core peak analysis. The charge density map (plane 110) of $\mathrm{Fe}_{1 / 4} \mathrm{TiS}_{2}$ and $\mathrm{Ni}_{1 / 4} \mathrm{TiS}_{2}$ (Figs. 8 and 9) in the energetic window $-6.8 /-1.4 \mathrm{eV}\left(E-E_{\mathrm{F}}\right)$ underlined the phe- 
nomenon. The magnitude of interaction is higher for $\mathrm{Ni}_{1 / 4} \mathrm{TiS}_{2}$ than for $\mathrm{Fe}_{1 / 4} \mathrm{TiS}_{2}$, leading to a higher sulfur $\mathrm{S} 2 /$ nickel interaction than sulfur S2/iron.

On the whole, the main interactions in $\mathrm{M}_{1 / 4} \mathrm{TiS}_{2}$ compounds occurred between $\mathrm{M}-\mathrm{S} 2-\mathrm{Ti1}$ atoms. Concerning $\mathrm{M}$ to Ti1 interactions, similar charge transfer was noted; the main difference between the three compounds is the electronic diffuse $\left(\mathrm{dz}^{2}\right.$ orbitals) character observed in the case of $\mathrm{Fe}_{1 / 4} \mathrm{TiS}_{2}$. The less directional character of the whole d electronic density (greater localization around the nuclei) for cobalt and nickel may explain the more pronounced interaction between $\mathrm{M}(\mathrm{Co}, \mathrm{Ni})$ and $\mathrm{S} 2$ atoms.

Considering now the STM results, remember that at relatively small bias voltage, and when the tip to surface interaction is negligible, the nature of an STM image is determined by both an electronic factor and a geometrical factor, originating from the exponential decrease of atomic orbital amplitude with distance. The electronic factor is specified by the local density around the Fermi level of filled or empty (according with the tip polarity) states of the outermost sulfur plane (in our case).

We examine the local density of states of each compound associated with the highest occupied bands in an energy window $\left(E_{\mathrm{F}}-0.3, E_{\mathrm{F}}\right) \mathrm{eV}$. By integrating the partial DOS of each sulfur type in the previous energy range $\left(E_{\mathrm{F}}-0.3 \mathrm{eV}\right)$ for the three compounds, we obtain the following results for the S2 3p and S1 3p participation in the total DOS:

\begin{tabular}{llll} 
& $\begin{array}{l}\mathrm{S} 2(\mathrm{Ti}, \mathrm{M}) 3 \mathrm{p} \\
(\%)\end{array}$ & $\begin{array}{l}\mathrm{S} 1(\mathrm{Ti}) 3 \mathrm{p} \\
(\%)\end{array}$ & Ratio \\
\cline { 2 - 4 } $\mathrm{Fe}_{1 / 4} \mathrm{TiS}_{2}$ & 1.20 & 1.25 & 1.04 \\
$\mathrm{Co}_{1 / 4} \mathrm{TiS}_{2}$ & 1.30 & 2.00 & 1.54 \\
$\mathrm{Ni}_{1 / 4} \mathrm{TiS}_{2}$ & 1.40 & 3.00 & 2.14
\end{tabular}

(\% are expressed in terms of the participation of $3 p$ orbital from one sulfur type to the total DOS). For each compound, note that these ratios are quasi constant over the energetic window: $E_{\mathrm{F}}-0.3 \mathrm{eV}$. It is of interest to note the inversion of the valence electronic density and the electronic density around the Fermi level for the different sulfur atoms in the inserted compounds. This phenomenon is obvious for $\mathrm{Ni}_{1 / 4} \mathrm{TiS}_{2}$ and could explain the clear differences between XPS and STM data.

The local density of filled sulfur states around the
Fermi level may be one argument to explain the experimental STM images. We can consider that the differentiation between the two sulfur atoms for $\mathrm{Ni}_{1 / 4} \mathrm{TiS}_{2}$ and $\mathrm{Co}_{1 / 4} \mathrm{TiS}_{2}$ could be due to different contributions to the electronic density of each around the Fermi level $\rho\left(E_{\mathrm{F}}-\mathrm{eV}\right)$.

Furthermore, we have noted for $\mathrm{Ni}_{1 / 4} \mathrm{TiS}_{2}$ images that one cell could be described by one light triangle and one dark triangle (Fig. 5b). Three sulfur atoms delimit each of them. These brightness differences could be due to electronic densities variations detected by the tip. Considering the surface layers, we can say that the light zone is aligned with a nickel atom and the dark zone is above an octahedral vacancy. The electronic density due to a nickel atom is then slightly detected by the tip in a second order interaction through the sulfur-titanium-sulfur layers and could explain the luminosity of the triangle.

Besides these comments on electronic features, we are conscious that only slab theoretical calculations taking into account the geometrical factors could clearly support this discussion. However, some preliminary arguments could be envisaged; the different sulfur atom chemical surroundings involve different electrostatic interactions between the subsurface metal layer (titanium atoms) and the top sulfur plane. Some chalcogen atoms (from the outer layer) could be at a higher height than the others (from the same plane) and could be highlighted by the tip because of the exponential link of the tunneling current with the surface to tip distance. There is a non-rigidity of the structure, resulting from the population of $d$ antibonding levels of titanium atoms and thus an elongation of $\mathrm{Ti}-\mathrm{S}$ bond [35]. Considering the change of the metal-sulfur distance and the different coordination for sulfur atoms ( $\mathrm{Ti}$ or $\mathrm{Ti}$ and $\mathrm{M}$ ), we can suggest that the structure differs from an ideal arrangement, especially for the surface atomic plane. Then, the different heights for sulfur atoms suggested previously may find their origin in electronic charge transfer. For these atoms, the surface to tip distance would be reduced and could explain the appearance of bright spots on the corresponding STM image. This phenomenon could be compared to surface local relaxation.

To be consistent with the interpretation given previously for $\mathrm{Ni}_{1 / 4} \mathrm{TiS}_{2}$ and $\mathrm{Co}_{1 / 4} \mathrm{TiS}_{2}$, the same explanation should be convenient for $\mathrm{Fe}_{1 / 4} \mathrm{TiS}_{2}$. We 
can suppose that for this last compound, the magnitude would not be sufficient to influence the tunneling current.

\section{Conclusion}

We have studied the electronic structure of inserted compounds $\mathrm{M}_{1 / 4} \mathrm{TiS}_{2}(\mathrm{M}=\mathrm{Fe}, \mathrm{Co}, \mathrm{Ni})$ by XPS, STM and theoretical calculations. The different behaviors observed are interpreted as different hostguest interactions. The chemical shifts of the core peaks have been mainly correlated with initial state effects, based on charge transfer which occurred from the inserted species to titanium and sulfur atoms. It is to be noted that the differentiation between titanium atoms, in terms of XPS spectra, is less obvious than for sulfur atoms, where two kinds of chalcogen atoms were clearly revealed. They are continuously more differentiated for $\mathrm{Ni}_{1 / 4} \mathrm{TiS}_{2}$ than for $\mathrm{Co}_{1 / 4} \mathrm{TiS}_{2}$ and $\mathrm{Fe}_{1 / 4} \mathrm{TiS}_{2}$. This phenomenon is interpreted as different magnitude of interaction between the inserted metal and the sulfur atoms coordinated with $\mathrm{M}$ and $\mathrm{Ti}$ atoms. Indeed, calculations have shown a less directional and diffuse character of the electronic density for $\mathrm{Ni}$ atoms than for $\mathrm{Co}$ and $\mathrm{Fe}$ atoms; this leads to more effective interactions for $\mathrm{M}$ atoms with first neighbors (S2) in the case of $\mathrm{Ni}_{1 / 4} \mathrm{TiS}_{2}$ compared to $\mathrm{Co}_{1 / 4} \mathrm{TiS}_{2}$ and $\mathrm{Fe}_{1 / 4} \mathrm{TiS}_{2}$.

By STM, we imaged the top sulfur plane of each compound. For the same crystallographic features concerning chalcogen atoms, the $\mathrm{Co}_{1 / 4} \mathrm{TiS}_{2}$ and $\mathrm{Ni}_{1 / 4} \mathrm{TiS}_{2}$ exhibit two types of sulfur atoms, while the $\mathrm{Fe}_{1 / 4} \mathrm{TiS}_{2}$ image is identical to the host compound $\mathrm{TiS}_{2}$. These differences were interpreted as arising from different electronic density around the Fermi level and different interactions between the top sulfur plane and the nature of the inserted species. However, only theoretical calculations performed with surface geometry optimization could unequivocally prove the previous discussion and will constitute our next work.

On the whole, sulfur atoms reveal themselves as very sensitive probes in XPS and STM experiments and we have highlighted their specific electronic behavior in the inserted phases $\mathrm{M}_{x} \mathrm{TiS}_{2}$ according to the nature of the inserted metal.

\section{References}

[1] J. Rouxel, in: F.A. Lévy (Ed.), Intercalated Layered Materials, P201, Reidel, Dordrecht, 1979.

[2] J.M. Vandenberg-Voorhoeve, in: P.A. Lee (Ed.), Optical and Electronic Properties, Reidel, Dordrecht, 1979, p. 423.

[3] G.V. Subba-Rao, M.W. Shafer, in: F.A. Lévy (Ed.), Intercalated Layered Materials, Reidel, Dordrecht, 1976.

[4] M.S. Whittinghan, Prog. Solid State Chem. 12 (1978) 41.

[5] M. Inoue, H.P. Hughes, A.D. Yoffe, Adv. Phys. 38 (5) (1989) 565.

[6] M. Inoue, M. Koyano, H. Negishi, Y. Veda, J. Phys. Soc. Jpn. 55 (1986) 1400.

[7] R.H. Friend, A.D. Yoffe, Adv. Phys. 36 (1987) 1.

[8] A. Zunger, A.J. Freeman, Phys. Rev. B 16 (1977) 906.

[9] M.H. Whangbo, J. Rouxel, L. Trichet, Inorg. Chem. 24 (1985) 1824.

[10] H.H. Weitering, T. Hibma, J. Phys. Condens. Matter. 3 (1991) 8535.

[11] A. Fujimori, S. Suga, H. Negishi, M. Inoue, Phys. Rev. B 38 (1988) 3676.

[12] T. Yamasaki, N. Suzuki, K. Motizuki, J. Phys. C: Solid State Phys. 20 (1987) 395.

[13] N. Suzuki, T. Yamasaki, K. Motizuki, J. Phys. C: Solid State Phys. 21 (1988) 6133.

[14] H. Martinez, S.F. Matar, C. Auriel, M. Loudet, G. PfisterGuillouzo, J. Alloys Comp. 245 (1996) 30-39.

[15] H. Martinez, C. Auriel, S.F. Matar, G. Pfister-Guillouzo, J. Electron. Spectrosc. Relat. Phenom. 87 (1997) 19-30.

[16] K. Motizuki, N. Suzuki, Mater. Sci. Forum 91-93 (1992) 381.

[17] J. Dijkstra, C.F. Bruggen, C. Haas, J. Phys. Condens. Matter. 1 (1989) 4297.

[18] L. Benoist, D. Gonbeau, G. Pfister-Guillouzo, F. Schmidt, G. Meunier, A. Levasseur, Solid State Ionics 76 (1995) 81.

[19] I. Martin, P. Vinatier, A. Levasseur, J.C. Dupin, D. Gonbeau, J. Power Sources 81 (1999) 306.

[20] J.C. Dupin, D. Gonbeau, I. Martin-Litas, P. Vinatier, A. Levasseur, J. Electron Spectrosc. Relat. Phenom. 120 (2001) 55.

[21] H. Martinez, C. Auriel, D. Gonbeau, M. Loudet, G. PfisterGuillouzo, Appl. Surf. Sci. 125 (1998) 259.

[22] H. Martinez, P. Azavant, M. Loudet, Surf. Sci. 400 (1998) 247.

[23] M. Inoue, H. Negishi, J. Phys. Chem. 90 (1986) 235.

[24] J.B. Goodenough, in: H. Reiss (Ed.), Progress in Solid State Chemistry, Pergamon, Oxford, 1971, Vol. 5.

[25] G.V. Subba Rao, M.W. Shafer, L. Tao, Mater. Res. Bull. 8 (1973) 1231.

[26] P. Blaha, K. Schwarz, J. Luitz, WIEN97, Vienna University of Technology, Vienna, 1997, improved and updated Unix version of the original copyrighted Wien-code, which was published by P. Blaha, K. Schwarz, P. Sorantin, S.B. Trickey, Comput. Phys. Commun. 59 (1990) 399.

[27] J.P. Perdew, S. Burke, M. Erbzerhof, Phys. Rev. Lett. 77 (1996) 3865. 
[28] P. Blöchl, O. Jempsen, O. Anderson, Phys. Rev. B 49 (1994) 16223.

[29] S.N. Magonov, M.H. Whangboo, Adv. Mater. 6 (1994) 355.

[30] R. Zimmermann, P. Steiner, R. Claessen, F. Reinert, S. Hüfner, P. Blaha, P. Dufek, J. Phys. Condens. Matter. 11 (1999) 1657.

[31] K. Dartigeas, L. Benoist, D. Gonbeau, G. Pfister-Guillouzo, G. Ouvrard, A. Levasseur, J. Electron Spectrosc. Relat. Phenom. 83 (1997) 45.
[32] J.I. Meakin, P.C. Klipstein, R.H. Friend, J. Phys. C 20 (1987) 271.

[33] J.H. Scofield, J. Electron Spectrosc. Relat. Phenom. 8 (1976) 129.

[34] P. Blaha, J. Phys. Condens. Matter. 3 (1991) 9381.

[35] H. Negishi, S. Ohara, Y. Takata, T. Yokoyama, M. Tarrigushi, M. Inoue, Mater. Sci. Forum 91-93 (1992) 603. 